\title{
Formação pedagógica em Educação Profissional e Tecnológica: análise de uma experiência com professores em exercício na rede pública estadual do Rio Grande do
}

\section{Norte}

\author{
Pedagogical training in Professional and Technological Education: analysis of an experience with \\ teachers working in the state public network of Rio Grande do Norte
}

Formación pedagógica en Educación Profesional y Tecnológica: análisis de una experiencia con docentes que trabajan en la red pública estatal de Rio Grande do Norte

Recebido: 08/11/2021 | Revisado: 13/11/2021 | Aceito: 30/11/2021 | Publicado: 11/12/2021

Emerson Carlos da Silva
ORCID: https://orcid.org/0000-0002-8433-4619
Escola Estadual Professor José Nogueira, Brasil
E-mail: emersoncarlos90@ @otmail.com
Aleksandre Saraiva Dantas
ORCID: https://orcid.org/0000-0001-9158-9372
Instituto Federal de Educação, Ciência e Tecnologia do Rio Grande do Norte, Brasil
E-mail: aleksandre.dantas@ifrn.edu.br

\begin{abstract}
Resumo
O presente trabalho tem por objetivo apresentar os resultados da elaboração e aplicação de uma proposta formativa para professores que desenvolvem suas atividades no âmbito da EPT. Essa proposta pautou-se em discussões sobre a formação docente, bases conceituais, práticas e teorias pedagógicas e Metodologias Ativas, voltados ao ensino no âmbito da EPT. A pesquisa de cunho qualitativo com abordagem bibliográfica trouxe alguns autores clássicos que são referências no âmbito da Educação Profissional e Tecnológica. Para tanto, usou-se um questionário avaliativo para coleta de dados, apropriando-se das falas dos entrevistados e analisando-as a luz da Análise de Conteúdo e comparando-as ao que definem esses autores sobre as especificidades que os docentes devem adquirir diante dessa modalidade, sendo isso imperativo ao entendimento e análise da problemática abordada. Desta forma, como resultados, pode-se afirmar que essa proposta formativa, mostrou-se bastante relevante para o contexto escolar que abrange a modalidade de EPT em sua estrutura curricular. Com as análises dos resultados observados, percebeu-se a afloração da reflexão e da conscientização oportunizada pelas discussões advindas dessa formação, e uma mudança de perspectivas diante da modalidade do EMI. Conclui-se, portanto, que a formação no molde proposto, ou seja, sendo alicerçada pelas teorias e metodologias fundamentadas na problematização, reflexão-crítica, possibilitou uma visão ampla e disponibilizou ferramentas para prática desses profissionais diante da EPT, ofertando contribuições significativas para as práticas no âmbito da Educação Profissional e Tecnológica dos professores participantes.
\end{abstract}

Palavras-chave: Formação pedagógica; Educação profissional e tecnológica; Prática docente.

\begin{abstract}
This work aims to present the results of the elaboration and application of a training proposal for teachers who develop their activities within the EPT. This proposal was based on discussions about teacher training, conceptual bases, pedagogical practices and theories, and Active Methodologies, aimed at teaching within the EPT. The qualitative research with a bibliographic approach brought some classic authors who are references in the field of Professional and Technological Education. Therefore, an evaluative questionnaire was used for data collection, appropriating the interviewees' statements and analyzing them in the light of Content Analysis and comparing them to what these authors define about the specificities that teachers must acquire in view of this modality, which is imperative to the understanding and analysis of the problem addressed. Thus, as a result, it can be stated that this training proposal proved to be quite relevant to the school context that encompasses the EPT modality in its curricular structure. With the analysis of the observed results, it was noticed the emergence of reflection and awareness brought about by the discussions arising from this training, and a change in perspectives regarding the EMI modality. It is concluded, therefore, that training in the proposed mold, that is, being based on theories and methodologies based on problematization, critical reflection, allowed a broad vision and provided tools for these professionals to practice in the EPT, offering significant contributions to the practices within the Professional and Technological Education of the participating teachers.
\end{abstract}

Keywords: Pedagogical training; Professional and technological education; Teaching practice. 


\begin{abstract}
Resumen
Este trabajo tiene como objetivo presentar los resultados de la elaboración y aplicación de una propuesta de formación para docentes que desarrollan sus actividades dentro del EPT. Esta propuesta se basó en discusiones sobre formación docente, bases conceptuales, prácticas y teorías pedagógicas y Metodologías Activas, orientadas a la docencia dentro del EPT. La investigación cualitativa con enfoque bibliográfico trajo algunos autores clásicos que son referentes en el campo de la Educación Profesional y Tecnológica. Por ello, para la recolección de datos se utilizó un cuestionario evaluativo, apropiándose de las declaraciones de los entrevistados y analizándolas a la luz del Análisis de Contenido y comparándolas con lo que estos autores definen sobre las especificidades que deben adquirir los docentes ante esta modalidad, lo cual es imperativo para la comprensión y análisis del problema abordado. Así, como resultado, se puede afirmar que esta propuesta formativa resultó ser bastante relevante para el contexto escolar que engloba la modalidad EPT en su estructura curricular. Con el análisis de los resultados observados, se advirtió el surgimiento de la reflexión y la toma de conciencia provocada por las discusiones surgidas de esta formación, y un cambio de perspectivas sobre la modalidad EMI. Se concluye, por tanto, que la formación en el molde propuesto, es decir, basarse en teorías y metodologías basadas en la problematización, la reflexión crítica, permitió una visión amplia y brindó herramientas para que estos profesionales ejerzan en el EPT, ofreciendo aportes significativos a las prácticas dentro de la Educación Profesional y Tecnológica de los docentes participantes.
\end{abstract}

Palabras clave: Formación pedagógica; Educación profesional y tecnológica; Práctica docente.

\title{
1. Introdução
}

A Educação Profissional e Tecnológica (EPT) tem sido permeada por diversas disputas no decorrer da sua história, e, ao longo das trajetórias das legislações que estruturaram essa modalidade, houve um dualismo de concepções (Ramos, 2014), pois a EPT ora era entendida como parte do ensino propedêutico, por ter o trabalho como eixo central na formação do homem como ser social, ora era vista como um simples treinamento voltado aos interesses do sistema produtivo capitalista. Nesta última concepção, a classe trabalhadora tende a ser expropriada dos saberes e conhecimentos mais complexos oferecidos à classe dominante, contentando-se com a instrumentalidade do ensino (Borges, 2017). Contrariando essa concepção, entendemos que a EPT deve ser implementada como subsídio para que o sujeito alcance sua completude, não apenas como instrumento mercadológico, mas para que o discente tenha o trabalho como princípio educativo, numa perspectiva emancipatória, de superação das dificuldades impostas pelo capitalismo.

Segue-se a isso a importância do ensino em EPT ter suas nuances em contraposição a qualificações imediatistas, fragmentárias, voltadas para atender apenas a um determinado contexto de mercado.

Diante disso, o professor torna-se elemento chave ao ensino em todas as modalidades e níveis. Sendo os docentes primordiais na construção dos processos de ensino, principalmente, o ensino em EPT, torna-se essencial que esse profissional busque aliar suas práticas e métodos de ensino aos preceitos do trabalho como princípio educativo, numa visão contrahegemônica, baseadas em conceitos como: politecnia, omnilateralidade e formação integral.

O professor atuante na Educação Profissional deve tornar-se um profissional reflexivo e crítico sobre suas ações e propenso à pesquisa, à atualização constante de suas atividades, tanto em sua área específica, quanto pedagógica, predisposto ao trabalho cooperativo e que tenha compreensão sobre as nuances do trabalho.

Entretanto, os processos formativos para os docentes que atuam na EPT são permeados por diversas lacunas. Esses professores, no decorrer de suas formações, muitas vezes, não tiveram formações pedagógicas que discutissem as bases que sustentam o ensino em EPT (Machado, 2008). Fato preocupante, tendo em vista as dificuldades impostas pelo capital à obtenção de uma educação integral (Moura, 2013).

Nessa perspectiva, essa pesquisa advém de um trabalho de dissertação vinculada ao Programa de Pós-graduação em Educação Profissional e Tecnológica (PROFEPT), a qual visou a elaboração e aplicação de uma proposta formativa para professores que desenvolvem suas atividades no âmbito da EPT e não possuíam formação voltada para essa temática, priorizando a discussão sobre as bases de sustentação, práticas e métodos voltados ao ensino em EPT, com o intuito de fomentar a qualidade do ensino nessa modalidade, buscando subsidiar a formação pedagógica docente para esse meio. Diante 
disso, a pesquisa trabalhou sobre a problemática: de que maneira uma formação pedagógica pode estimular a reflexão sobre a prática docente dos professores inseridos no ensino em EPT?

Dessa forma, apresenta-se nesse trabalho os resultados obtidos com base nos relatos dos docentes que participaram da formação, os quais foram obtidos por meio de questionários avaliativos, os quais oportunizaram aos participantes flexibilidade de tempo, permitindo que respondessem no momento que julgarem mais conveniente, garantia do anonimato das respostas, a exclusão de possíveis opiniões pessoais (Gil, 2008); além de maior objetividade, clareza e adequação às rotinas e à realidade desses docentes participantes.

\section{Metodologia}

Essa pesquisa ampara-se na busca de proposituras de uma formação didático-pedagógica para professores que já estão desenvolvendo atividades no âmbito da EPT, mas que não contemplaram formação específica para atuação nessa modalidade.

Diante disso, a pesquisa compreende-se em um trabalho de cunho qualitativo, a qual envolve a obtenção de dados descritivos pelo contato direto do pesquisador com a situação estudada, buscando sua compreensão segundo a perspectiva dos sujeitos (Godoy, 1995). Além disso, construiu-se de maneira descritiva, descrevendo entendimentos de professores quanto ao desenvolvimento do trabalho que realizam na EPT (Gil, 2008). Sobre os procedimentos técnicos, essa investigação ancorou-se numa abordagem bibliográfica, tendo em vista que foi desenvolvida com base em material já produzido, composto por livros, artigos científicos, dentre outros periódicos, considerando que essa técnica proporciona uma cobertura ampla de materiais para serem utilizados como suporte (Gil, 2008).

A coleta de dados foi realizada por meio do questionário avaliativo da formação, a fim de analisar as percepções dos professores participantes da pesquisa quanto às possíveis contribuições acarretadas pela aplicação dessa formação pedagógica para a sua prática profissional no contexto da EPT, mais ainda, como uma forma de apreender se a formação ofertada conseguiu despertar a reflexão, a consciência crítica sobre o papel do professor diante da EPT, inclusive, se as ferramentas pedagógicas utilizadas, viabilizaram transformações na mentalidade dos participantes para suas atividades nessa modalidade.

A análise dos dados foi subsidiada pela Análise de Conteúdo (AC), um instrumento utilizado como meio de equacionar formas para uma melhor interpretação de mensagens ou conteúdo em pesquisas qualitativas, oportunizando a superação de incertezas e o enriquecimento de leituras (Bardin, 2006). Esse método oportunizou a criação de categorias de análise, as quais contribuíram para inferenciar com maior precisão os resultados e as análises da pesquisa.

O questionário avaliativo da proposta formativa constituiu-se por oito quesitos sobre a formação pedagógica, os quais foram representados, respectivamente, por Q1 a Q8. Em relação a esses quesitos, resumidamente: Q1 trouxe a indagação sobre a relevância e correlação dos conteúdos abordados diante da formação para EPT; Q2 questionou se as discussões durante a formação oportunizaram novos conhecimentos; Q3 indagou se os conhecimentos obtidos podem colaborar para prática dos participantes na EPT; Q4 trouxe o questionamento sobre a viabilidade da teoria Histórico-Critica e se essa tem potencial de embasar a atividade docente no campo da EPT; em Q5, pergunta-se sobre a possibilidade da implementação das metodologias ativas inseridas na EPT, se são viáveis para esse contexto educacional; Q6 indaga-se se a formação possibilitou subsídios, reflexão com vista a melhorar a prática docente dos participantes no âmbito da EPT; Q7 buscou instigar os respondentes a avaliarem a metodologia do curso, sendo provocados a destacarem os pontos positivos e negativos dessa; e, por último, em Q8 foi disponibilizado o espaço para sugestões da formação na visão dos participantes. Considerando os dez docentes que responderam ao questionário, esses foram classificados, respectivamente, de P1 a P10.

\section{Considerações sobre formação docente para Educação Profissional e Tecnológica}

O sistema educacional brasileiro é composto por diferentes modalidades de ensino. Dentre elas, temos a Educação 
Profissional e Tecnológica (EPT), integrando-se aos diversos níveis de ensino, às dimensões do trabalho, da ciência e da tecnologia (Brasil, 2018). O sistema de ensino é diretamente influenciado pelo contexto político, social e cultural, constituídos historicamente. A EPT, estando intimamente relacionada ao trabalho, torna-se ainda mais suscetível a essa dinâmica, principalmente quando consideramos sua centralidade no sistema capitalista. Consoante a isso e a suas especificidades, são muitos os desafios quanto à formação de professores para atuarem nessa modalidade educativa.

Apesar da importância da qualificação para o trabalho docente nessa área, principalmente devido as especificidades da EPT, muitas vezes, os profissionais que nela atuam não dispõem de formação pedagógica voltada para a atuação nessa modalidade. Os professores licenciados, responsáveis pelos conhecimentos propedêuticos, e os bacharéis, responsáveis pelas disciplinas técnicas, não realizaram discussões específicas sobre o ensino na EPT no decorrer de suas graduações. Isso é preocupante, tendo em vista a lógica mercadológica que o capitalismo impõe à sociedade, e a crescente implantação de Educação Profissional na atualidade.

Historicamente, a intenção de formação de professores, principalmente no âmbito de EPT, teve uma face, de certa forma, incipiente no cenário brasileiro, deixando várias lacunas ao longo do processo, com deficiências em pensamentos formativos consistentes e políticas públicas amplas e duradouras (Machado, 2008).

Nesses processos, em que vários desses profissionais não tiveram formação didática-pedagógica voltadas ao ensino, muito menos em EPT, ou os que tiveram, mas não abrangeram a Educação Profissional, torna-se urgente uma complementação pedagógica para a compreensão das dinâmicas que ocorrem na EPT, principalmente para os profissionais imersos e que estão atuando nessa modalidade, seja qual for a sua base formativa.

Os desafios e problemas a serem superados no âmbito da Educação Profissional, mais especificamente, envolvem a formação docente intrínseca para as modalidades que se integram a EPT, acrescida das demandas e exigências propostas pela globalização e as inovações tecnológicas. Para Machado (2011),

[...] o desafio da formação de professores para a EPT manifesta-se de vários modos, principalmente quando se pensa nas novas necessidades e demandas político-pedagógicas dirigidas a eles: mais diálogos com o mundo do trabalho e a educação geral; práticas pedagógicas interdisciplinares e interculturais; enlaces fortes e fecundos entre tecnologia, ciência e cultura; processos de contextualização abrangentes; compreensão radical do que representa tomar o trabalho como princípio educativo; perspectiva de emancipação do educando, porquanto sujeito de direitos e da palavra. (Machado, 2011, p. 694).

Seguindo-se à falta de concretude concernente a uma formação docente, a Lei de Diretrizes e Bases da Educação Nacional (LDB), Lei 9.394/96, apresentou uma proposta de formação geral para professores, com alcance à EPT, com importantes pontos em destaque, incluindo a defesa da relação entre teoria e prática e, mais ainda, o estabelecimento da prática de ensino nessa área. Regulamentando os apontamentos sobre Educação Profissional dessa LDB, o Decreto 2.208/97 expande a possibilidade de atuação de outros profissionais além dos professores; instrutores e monitores, com suas experiências, também poderiam lecionar na Educação Profissional (Machado, 2015). Enxerga-se com esses dispositivos, a falta de ênfase na formação docente para EPT, uma valorização explicita da prática sobre a teoria, e uma despreocupação quanto a um embasamento didático-pedagógico desses profissionais.

Um fato preocupante, em relação à formação docente, apresentou-se no Decreto 5.154/2004, tendo em vista que, mesmo esse decreto tratando sobre regulamentações voltadas à EPT, complementando alguns artigos da LDB e revogando o Decreto 2.208/97, em suas entrelinhas, não fez qualquer menção à formação específica de professores para a Educação Profissional (Santos, 2008).

Já a Resolução CNE 02/2015 apresenta vários pontos quanto à formação inicial e continuada de docentes para a Educação Básica. Em seu Art. $3^{\circ}$, menciona Educação Profissional como alvo dessas formações, mas não apresenta, em seu 
corpo, nenhum aprofundamento específico sobre diretrizes formativas para esse campo.

Essas legislações, apesar de suscitarem partes específicas voltadas a abordagem da Educação Profissional, tangem a superficialidade sobre planejamentos e efetivações de uma estruturação ampla para formação docente em EPT. Essas legislações, não apresentaram parâmetros ou diretrizes substanciais para perpetuar a formação de professores para atuarem nessa modalidade.

Com isso, uma lógica deficitária, com pensamentos destoantes, sem uma base unitária e consistente sobre a formação docente para a EPT, tornou-se tema recorrente no cenário educacional brasileiro. Santos (2008) faz alguns apontamentos sobre problemas na formação docente para a EPT, como: oferta de formação inicial nas universidades, licenciaturas que, quando existem, não se voltam para a EPT; precariedade na oferta de cursos específicos por área; pouca articulação entre os saberes científicos, técnicos, tácitos e pedagógicos; oferta de formação incapaz de atender à demanda; ausência de formação pedagógica; entre outros.

Formulações e proposituras são suscitadas constantemente, principalmente com a crescente oferta de pós-graduações voltadas à EPT, com o objetivo de amenizar esses problemas que cercam esse campo educacional. Há diversas discussões e defesas sobre onde deve acontecer o processo formativo para EPT, se na formação inicial ou continuada e, também, sobre a base curricular que deve ser abordada nesse processo. Contudo, as formações docentes relacionadas à EPT ainda são bastante insipientes e devem ser sistematizadas e ofertadas de forma contínua e periódica. Independente do formato e modalidade que se proponham, essas formações devem fazer parte do cotidiano dos docentes inseridos na Educação Profissional.

\section{Estruturação e Metodologia da Formação Proposta}

Essa formação foi estruturada em formato de minicurso, opção feita pelo fato da melhor adequação à rotina dos professores participantes da pesquisa. É importante ressaltar que não pretendíamos, simplesmente, realizar um "remendo emergencial", mas sim, levar uma discussão e reflexão para o chão da escola no qual o professor desenvolve diretamente suas atividades.

Essa formação, considerando o contexto pandêmico acarretado pelo vírus COVID-19, que possui alta taxa de transmissibilidade, consequentemente, levando ao distanciamento social, foi viabilizado totalmente de forma remota, buscando implantar medidas que mantivessem nossas atividades da melhor forma possível de modo a preservar a saúde e segurança de todos e, sendo à distância, a uma maior flexibilidade em adequação às rotinas dos participantes.

Essa proposta estruturou-se em um formato que se utilizou de momentos síncronos (com encontros por videoconferências, os quais foram momentos de discussões sobre os conteúdos abordados nas atividades e leituras dos materiais previamente disponibilizados) e assíncronos, tendo em vista a disponibilização dos materiais de estudos por meio de ambientes virtuais de aprendizagem, grupos de WhatsApp e por e-mail. Ressaltamos a possibilidade da participação de convidados nos encontros por videoconferência, a fim de enriquecer as discussões e debates, nesses momentos, corroborando para a consolidação e a qualidade dessa formação.

Durante as fases de aplicação da formação, os materiais utilizados para os estudos, como artigos e outras atividades, foram dispostos no Google Classroom, uma plataforma virtual e gratuita, na qual os participantes foram cadastrados, dandolhes, assim, acesso aos conteúdos utilizados em cada módulo, antes dos encontros síncronos e, também, para realizarem as atividades propostas.

Os encontros virtuais aconteceram atravé de webconferências, via Google Meet, a fim de debater, esclarecer, vivenciar um ambiente de aula sobre os conteúdos propostos aos professores participantes, realizando uma troca de conhecimentos e apreensões de forma colaborativa.

A formação foi ofertada em quatro módulos, apresentados abaixo: 
Quadro 1 - Conteúdos, objetivos e referências básicas utilizadas nos módulos do curso de formação "Sentidos da EPT: vamos refletir?"

\begin{tabular}{|c|c|c|c|}
\hline Módulos do minicurso & Conteúdos abordados & Objetivos & Referências bases \\
\hline $\begin{array}{l}1^{\circ} \text { módulo: Histórico } \\
\text { sobre a formação de } \\
\text { professores e a EPT no } \\
\text { cenário brasileiro. }\end{array}$ & $\begin{array}{l}\text { Nesse primeiro momento, foi posto em } \\
\text { estudos e discussões com os participantes, } \\
\text { como se estruturou a formação docente } \\
\text { para a educação profissional, embasando- } \\
\text { se nas legislações e autores referencias no } \\
\text { assunto. }\end{array}$ & $\begin{array}{l}\text { Entender como se deu a trajetória de } \\
\text { formação de professores no Brasil. } \\
\text { Problematizar os apontamentos para } \\
\text { formação docente considerados à } \\
\text { EPT. }\end{array}$ & $\begin{array}{l}\text { Saviani, 2009; } \\
\text { Scheibe, 2008; } \\
\text { Machado, 2008; } \\
\text { Moura, 2014. }\end{array}$ \\
\hline $\begin{array}{l}2^{\circ} \text { módulo: Bases teóricas } \\
\text { que sustentam o ensino- } \\
\text { aprendizagem em EPT. }\end{array}$ & $\begin{array}{l}\text { No segundo momento, explanou-se } \\
\text { conceitos que subsidiam o ensino nessa } \\
\text { modalidade, e suas perspectivas políticas, } \\
\text { teóricas e práticas, a partir do estudo de } \\
\text { autores basilares que se debruçam a } \\
\text { pensar sobre Educação Profissional. }\end{array}$ & $\begin{array}{l}\text { Discutir e conhecer bases conceituais } \\
\text { que sustentam o ensino vinculado a } \\
\text { EPT. } \\
\text { Refletir sobre a importância do ensino } \\
\text { ser pautado por uma visão de } \\
\text { formação integral, politécnica, } \\
\text { omnilateral. }\end{array}$ & $\begin{array}{l}\text { Ciavatta, 2014; } \\
\text { Manacorda, 2007; } \\
\text { Moura, 2013; } \\
\text { Saviani, } 1989 .\end{array}$ \\
\hline $\begin{array}{l}3^{\circ} \text { módulo: Pedagogia } \\
\text { Histórico-Crítica e as } \\
\text { Práticas pedagógicas em } \\
\text { EPT. }\end{array}$ & $\begin{array}{l}\text { Nesse terceiro momento, buscou-se } \\
\text { apresentar os principais pontos da } \\
\text { pedagogia Histórico-Crítica, de modo a } \\
\text { demonstrar a afinidade desta vertente } \\
\text { pedagógica com os princípios filosóficos } \\
\text { da EPT. }\end{array}$ & $\begin{array}{l}\text { Discutir os possíveis benefícios } \\
\text { trazidos pela pedagogia Histórico- } \\
\text { Crítica para o trabalho docente em } \\
\text { sala de aula, considerando o contexto } \\
\text { da EPT. }\end{array}$ & $\begin{array}{l}\text { Freire, 1987; } \\
\text { Libâneo, 2010; } \\
\text { Gasparin; Petenucci, 2008; } \\
\text { Saviani, 2011; } \\
\text { Mazzeu, 1998. }\end{array}$ \\
\hline $\begin{array}{l}4^{\mathrm{o}} \text { módulo: Propostas } \\
\text { metodológicas para EPT. }\end{array}$ & $\begin{array}{l}\text { Nesse último momento, discutiu-se sobre } \\
\text { metodologias de ensino, com ênfase em } \\
\text { metodologias ativas, demonstrando que as } \\
\text { estratégias da Sala de Aula Invertida, a } \\
\text { Metodologia da Problematização e a } \\
\text { Aprendizagem Baseada em Projetos se } \\
\text { aplicam como metodologias inovadoras } \\
\text { consonantes com os princípios da } \\
\text { pedagogia histórico-critica e a base } \\
\text { conceitual da EPT, na perspectiva de } \\
\text { formação crítica dos discentes. }\end{array}$ & $\begin{array}{l}\text { Relacionar os apontamentos de } \\
\text { Metodologias Ativas às bases } \\
\text { conceituais da EPT e à pedagogia } \\
\text { Histórico-Crítica. } \\
\text { Gerar a reflexão sobre as } \\
\text { potencialidades das Metodologias } \\
\text { Ativas para prática docente no âmbito } \\
\text { da EPT. }\end{array}$ & $\begin{array}{l}\text { Araújo \& Frigotto, 2015; } \\
\text { Freire, 1996; } \\
\text { Moreira \& Ribeiro, 2016; } \\
\text { Gemignani, 2012; } \\
\text { Valente, 2014; } \\
\text { Silva \& Kalhil, } 2015 .\end{array}$ \\
\hline
\end{tabular}

Fonte: Autores (2020).

A aplicação foi pautada e subsidiada por princípios da pedagogia Histórico-Crítica. Essa corrente surge da necessidade demonstrada por educadores brasileiros em superar os limites das pedagogias não críticas, como a tradicional, a tecnicista e a crítico-reprodutivista, com intuito, também, de ultrapassar os pressupostos da escola como aparelho ideológico do Estado e a escola dual (Saviani, 2011). Essa pedagogia, pelo foco na transformação social, torna-se de grande relevância para o contexto educacional brasileiro, principalmente no ambiente de formação em EPT, "pois evidencia um método diferenciado de trabalho, especificando-se por passos que são imprescindíveis para o desenvolvimento do educando" (Gasparin \& Petenucci, 2008, p. 04).

Nessa perspectiva, trabalhou-se considerando a vivência e as experiências cotidianas dos professores em suas práticas de ensino, estimulando-os à reflexão-crítica sobre as atividades que estão desenvolvendo no contexto da EPT em que se inserem (esse ponto correlaciona-se a Prática Social Inicial). Essa nuance foi posta em análise, problematizada e relacionada a outras dimensões, suscitando a importância do debate sobre a Educação Profissional, equivalendo, então, à Problematização.

Por conseguinte, através de discussões, debates, compartilhamentos de conhecimentos, ofertados nos encontros remotos e, também, com a concretização de estudos dos materiais disponibilizados e as atividades propostas, almejou-se promover sensibilização e reflexões sobre novas ideias e conhecimentos quanto ao campo da EPT, com a junção entre sua prática docente cotidiana e o conhecimento científico, etapas essas equivalentes à Instrumentalização e à Catarse. Com isso, possibilitou-se uma nova visão aos professores, o que, em outros instantes, poderá gerar uma reflexão sobre suas práticas docentes na Educação Profissional. Esse último instante da formação corresponde, numa perspectiva Histórico-Crítica, à Prática Social Final.

Nessa proposta, foram disponibilizadas atividades de modo a exercitar e refletir sobre os conteúdos abordados. Em uma das atividades finais, lançou-se o desafio da elaboração de um plano de aula, pelo professor, para sua disciplina ministrada 
na EPT, considerando as metodologias adotadas no curso e a base teórica Histórico-Crítica, visando alcançar uma prática que se coadune com os princípios de uma educação politécnica e omnilateral. Essa idealização da formação politécnica e omnilateral deve tornar-se elemento chave e objetivo norteador do trabalho docente em EPT, pois traz a ótica da formação ampla dos sujeitos, em suas múltiplas totalidades (Frigotto, 2012); o professor, nesse sentido, deve criar caminhos para isso, como o trabalho pautado na interdisciplinaridade, integração, na problematização, na simbiose entre teoria e prática, superação desse dualismo, ou seja, a educação integrada devem ser guias para uma educação de qualidade, humanizada, crítica-reflexiva na formação de todos (Ciavatta, 2014), oportunizando a seus alunos subsídios para a formação integral, defendida nas bases teóricas da Educação Profissional.

Na aplicação, para uma melhor exequibilidade, disponibilizou-se um período de uma semana para conclusão de cada módulo. Em princípio, acontecendo os respectivos estudos, por meio de leituras e de vídeos (de modo assíncrono). Passada essa fase, culminando com a videoconferência/webconferência (modo síncrono), com o auxílio do Google Meet, buscando, assim, um maior aprofundamento nas discussões e debates sobre os temas estudados durante a semana.

Dessa forma, buscou-se ofertar meios para gerar reflexão e para potencializar uma possível transformação nas práticas exercidas por esses professores no ensino em EPT, visando a melhoria do ensino nessa modalidade.

\section{Reflexões e Resultados Advindos da Formação Pedagógica}

Apesar das deficiências formativas para atuação no campo da Educação Profissional, ou seja, no contexto da falta de formações pedagógicas especificas para EPT, os professores participantes mostraram bastante interesse e desenvoltura nas discussões proporcionadas pela aplicação da formação proposta nessa pesquisa.

Diante das respostas aferidas pelos professores participantes sobre a avaliação da formação, analisadas a luz da Análise de Conteúdo, construiu-se as seguintes categorias: conhecimentos adquiridos e reflexões à luz das discussões sobre EPT; contribuições para prática docente no EMI; embasamento teórico para EPT; potencial das Metodologias Ativas para o trabalho docente no EMI; e avaliação da formação. Essas categorias formaram a base para as discussões e inferências dessa pesquisa.

Sobre a categoria "Conhecimentos adquiridos e reflexões à luz das discussões sobre EPT", os docentes relataram que os conteúdos trabalhados foram "relevantes", “extremamente valiosos", "com bastantes aspectos inovadores", "acrescentaram na qualificação profissional", entre outros. Nesse cenário, destaca-se a fala de P6 que afirmou: "eu gostei dos conteúdos, porque muito do que foi ministrado eu não conhecia".

Além disso, os docentes afirmaram que a formação ofertou conhecimentos novos, que evidenciam que a proposta supriu problemáticas advindas da especificidade e da falta de discussões no chão da escola. Essa falta de discussões nos ambientes de ensino já havia sido apontada por Moura (2014), como um dos problemas mais urgentes a ser corrigido. A partir disso, evidencia-se, ainda mais, a contribuição dessa proposta para o campo da prática docente na EPT.

Os participantes avaliaram que, de forma geral, essa formação trouxe bastante reflexão em relação à docência nessa modalidade de ensino, oportunizando possibilidades, ferramentas que os provocaram a repensar as práticas docentes no âmbito do EMI. Esse processo reflexivo, segundo Gariglio \& Burnier (2012), é essencial para o trabalho docente, tendo em vista que a rotina e a repetição fazem o conhecimento prático tornar-se tão espontâneo que os profissionais tendem a não mais refletirem sobre o que estão fazendo. Essa reflexão torna-se um passo fundamental para a possível melhoria da prática docente nessa vertente educacional. Com essa transformação da mentalidade e esses conhecimentos pedagógicos específicos para EPT, podem colaborar para uma mudança de postura e de ações no trabalho desses professores.

Sobre a categoria "Contribuições para prática docente no EMI", os professores afirmaram que os conhecimentos obtidos e discutidos durante a formação possuem bastante potencial para colaborarem com as suas práticas em sala de aula 
diante da EPT. Esse fato demostra o potencial de aplicabilidade e embasamento oportunizado pela pedagogia Histórico-Crítica e as Metodologias Ativas estudadas e discutidas durante a formação. Segue o relato de alguns professores quando indagados se os conteúdos abordados poderiam embasar suas práticas no EMI,

P1. Sim, essa teoria pode embasar a minha prática pedagógica na EPT integrada ao Ensino Médio. De fato, seus pressupostos estão presentes em documentos que norteiam a educação e o currículo das escolas há muito tempo, sendo identificados inclusive em livros didáticos cuja construção do conhecimento se dá a partir da realidade dos alunos. Embora ainda encontre dificuldades para ser plenamente efetivada, visto que nem sempre conseguimos integrar teoria e prática, é viável e pode contribuir para a formação de sujeitos mais críticos e aptos para a vida em sociedade.

P2. Sim. Desenvolver o senso crítico ao mesmo tempo que contextualiza de acordo com a realidade que a sociedade vive. Todos os conteúdos, independente de qual seja, devem ser expostos de forma a desenvolver no alunado o senso crítico, não basta estar conceituado, historicizado, é necessário fazer uma relação com o momento vivido e questionarmos para que serve.

Observa-se, nessa perspectiva, que a formação pedagógica ofertada, sendo alicerçada pelas teorias e metodologias fundamentadas na problematização e na reflexão-crítica, viabilizou uma visão ampla e ofertou subsídios e ferramentas para prática desses profissionais diante da EPT, tendo em vista, esses afirmarem que essa proposta formativa possibilitou um delineamento teórico-metodológico para suas práticas nessa modalidade de ensino. Diante disso, percebe-se uma estimulação para os docentes tornarem-se profissionais que sabem o que, como e por que fazer, e a refletirem constantemente sobre sua atividade docente, propondo-se a ensinar e contribuir com o desenvolvimento idôneo bem como adequado de seus alunos para a vivência social e profissional, de forma a tangenciar a simples qualificação para o mercado de trabalho, ou melhor, ultrapassar o trabalho estritamente manual e prático criticado por Kuenzer (1997).

Considerando a categoria "Embasamento teórico para EPT", os docentes afirmaram que a teoria Histórico-Crítica pode embasar suas práticas no Ensino Médio Integrado, principalmente, no contexto de sala de aula. Na fala dos educadores, destacam-se termos como "senso crítico", "contextualização", "transformação social" e "problematização da realidade". Essas relações evidenciam uma apropriação, pelos docentes, dos fundamentos constituintes dessa pedagogia e suas potencialidades, mais ainda, de acordo com Barbosa e Fernandes (2018), incitam a construção de meios didáticos educacionais que potencializam a formação de uma sociedade justa através da educação. Com essas observações e com base nos apontamentos de Ciavatta (2014), sobre formação integral, é muito importante essa tomada de consciência pelos docentes que atuam nessa modalidade, pois a prática alicerçada por essa teoria tende a afastar-se de uma visão de formação fragmentária, unilateral, tecnicista e possibilita a transformação do ser para vida.

Ao atuar em um campo educacional que sofre intensas disputas sociais, ou seja, um processo formativo com base no trabalho como princípio educativo, em que o público alvo constitui-se predominantemente pelos filhos da classe trabalhadora (Ramos, 2014), os professores da EPT devem desenvolver suas práticas educativas comprometidas com a formação integral desses indivíduos, instituindo a problematização da realidade e possibilidades para transformação social. Surge, desse contexto, a importância da reflexão relatada pelos participantes da pesquisa sobre as potencialidades da pedagogia HistóricoCrítica para suas práticas, justamente, por essa apresentar-se como uma alternativa capaz de promover a contextualização do saber e a consequente aproximação entre teoria e prática no processo educativo.

Para a categoria "Potencial das Metodologias Ativas para o trabalho docente no EMI", os participantes consideraram essas metodologias muito proveitosas como instrumento pedagógico para o ensino em sala de aula no âmbito do EMI. É possível observar, em seus relatos, aproximações com base nas discussões e reflexões advindas da formação, entre essas metodologias e as atividades que já desenvolvem em suas práticas, isso pressupõe a tomada de consciência fundamentada teoricamente e instituída pela reflexão-crítica de suas ações. Salienta-se que, entre as Metodologias Ativas, foram abordadas, 
especificamente, a Metodologia da Problematização, a Aprendizagem Baseada em Projetos e a Sala de Aula Invertida, julgadas mais apropriadas para o contexto daquele ambiente escolar.

Essas metodologias, quando inseridas nas práticas de ensino, em especial na EPT, oportunizam ao docente o trabalho com base na contextualização, na interdisciplinaridade, na problematização, com apoio dos processos tecnológicos, quais, para Gemignani (2012), potencializam uma educação transformadora da sociedade. Além disso, disponibiliza um leque de ferramentas que podem moldar-se a diferentes realidades e a medida das necessidades, sendo elementos de mediação e construção de conhecimentos teóricos, práticos e com significado social para os estudantes (Moreira \& Ribeiro, 2016).

Sobre as Metodologias Ativas, destacaram-se as seguintes falas de P1, P4 e P10,

P1. As propostas de metodologias ativas favorecem uma aprendizagem significativa e estão muito mais alinhadas às atuais demandas do processo ensino-aprendizagem. Embora a existência de tais metodologias pressuponha mudanças e ajustes por parte de todos os envolvidos no processo educativo, certamente é possível implementá-las com sucesso. P4. As metodologias ativas trazem mais significado aos conhecimentos discutidos na sala de aula. Sem dúvida, a sua implementação é viável, mas seria necessária uma adaptação profunda do curriculum escolar, bem como uma formação continuada dos docentes.

P10. As metodologias ativas de ensino-aprendizagem são necessárias para uma prática docente no processo de formação do aluno no Ensino Médio Integrado.

Esses relatos demostram percepções e reflexões positivas acarretadas pelos estudos e discussões sobre as Metodologias Ativas de ensino-aprendizagem durante a formação, os quais compreenderam a importância de o ensino ser pautado pela problematização da realidade, pela aprendizagem com significado, autônoma, tendo o aluno como centro, o aprendizado com significado social, isso no contexto do EMI. Sobretudo, considerando, segundo Moreira e Ribeiro (2016), que o uso das Metodologias Ativas de ensino pode alavancar a formação cidadã, crítica e uma formação profissional ampla, à medida que instiga o desenvolvimento de sujeitos autônomos e capazes de tomar decisões mais acertadas.

Analisando a categoria "Avaliação da formação", os professores participantes consideraram essa proposta de formação pedagógica, sua estruturação, organização, conteúdos e metodologia abordada, bastante positivas. Em seus relatos, destacaram-se termos como "motivação", "possibilidades", "aprendizado concreto", "reflexão". Tais ponderações refletem a importância dessas propostas formativas serem instituídas dentro dessas instituições de ensino. Isso significa que elas devem acontecer no chão da escola, que muitas vezes, são expropriadas dos conhecimentos constituídos nas academias, sendo esse um ponto bastante gratificante verificado nessa formação, gratificante no sentido de termos a possibilidade de intercalar um conhecimento construído na academia ao ambiente escolar.

Diante dessa apreciação realizada, a proposta formativa mostrou-se bastante relevante para o contexto escolar que abrange a modalidade de EPT em sua estrutura curricular. Com as análises dos resultados observados, a partir dos relatos dos docentes participantes, percebeu-se o aflorar da reflexão e da criticidade, oportunizadas pelas discussões advindas dessa formação. Como também, uma mudança de perspectivas nos pensamentos e ações diante da modalidade do EMI.

\section{Considerações Finais}

O objetivo desta pesquisa foi promover, sob uma perspectiva Histórico-Crítica, uma formação pedagógica para professores que atuam na Educação Profissional e Tecnológica na Escola Estadual Professor José Nogueira no Município de Mossoró-RN. Diante disso, buscou-se, por meio das discussões sobre as nuances que cerceiam a Educação Profissional, considerando as bases conceituais, práticas e métodos voltados ao ensino na EPT, incentivar os docentes a realizarem, constantemente, reflexões a respeito das práticas que desenvolvem e que poderão desenvolver sob essa nova perspectiva sobre a EPT e sua defesa de uma educação integral, politécnica. 
Torna-se imperioso a formação docente dos profissionais que atuam na EPT, principalmente devido as especificidades e ao afastamento quanto aos conhecimentos nessa área demostrado pelos pesquisados. Percebeu-se, ao término da pesquisa, que a lacuna formativa dos professores que estão inseridos na EPT é bastante deficitária, muitas vezes inexistentes. Essa constatação oportuniza um leque de problemáticas que pode embasar futuras pesquisas dessa temática.

Evidencia-se, com isso, que a EPT evoca dos docentes conhecimentos e saberes que complementem suas formações, fundamentando suas práticas nessa modalidade. Assim, urge a importância de processos formativos constantes, sendo a formação continuada e aperfeiçoamentos, ferramentas indispensáveis para os professores que encontram-se desenvolvendo suas atividades na Educação Profissional e não foram contemplados com essas formações específicas. Nesse sentido, a formação pedagógica apresentada e aplicada pôde contribuir para sanar essas lacunas formativas, além de correlacionar agilidade, flexibilidade e praticidade de aplicação para docentes em pleno exercício, com potencial de replicação nos ambientes que ofertem a modalidade de EPT.

A formação didático-pedagógica aqui apresentada desenvolveu-se a partir das discussões e reflexões sobre os apontamentos das bases conceituais que sustentam a EPT, a teoria Histórico-Crítica, práticas e métodos voltados ao ensino nessa modalidade, pautando-se numa visão de educação integral e politécnica. Esse produto demonstrou um potencial significativo, no tocante à assimilação por meio das discussões decorridas, nas quais os docentes transpareceram novas percepções e transformações de entendimentos sobre os sentidos e objetivos do ensino na EPT.

Durante o processo formativo, os professores foram estimulados constantemente a refletir e problematizar o ensino em uma modalidade que traz o trabalho como princípio educativo, numa perspectiva de tangenciar um ensino simplesmente conteudista, unilateral e viabilizar um ensino numa visão ampla que considere os ideais da práxis educativa. Todas essas nuances foram tratadas e debatidas ao longo da aplicação.

De acordo com o relato dos participantes, a proposta formativa, ou seja, esse Produto Educacional, pautando as discussões sobre as bases conceituais, práticas e métodos voltados ao ensino na EPT, embasada na abordagem HistóricoCrítica, oportunizou contribuições significativas para o trabalho docente no âmbito da Educação Profissional integrada ao Ensino Médio.

Por conseguinte, pode-se afirmar que os objetivos foram alcançados, tendo em vista que a proposta formativa didático-pedagógica em EPT para professores em exercício na Educação Profissional no município de Mossoró-RN, foi desenvolvida e aplicada, proporcionando aos professores participantes uma reflexão, fundamentada teoricamente, sobre as práticas que desenvolvem e que poderão desenvolver, sob esse novo olhar diante da EPT. Conclui-se, portanto, que essa proposta estruturada pode contribuir significativamente para mitigar lacunas formativas dos profissionais que atuam no EMI, potencializando uma prática docente que viabilize os apontamentos instituídos pela EPT.

Além disso, espera-se que essa pesquisa, conjuntamente a seus resultados, possa contribuir e incentivar futuras pesquisas no âmbito da EPT, mais especificamente, trabalhos relacionados à formação docente para Educação Profissional, área que perpassa por diversas lacunas e requer uma atenção crítica para superação desses obstáculos.

\section{Referências}

Barbosa, S. H. P. B., \& Fernandes, M. C. S. G. (2018). O papel do professor na pedagogia histórico-crítica: contraponto ao movimento escola sem partido. Nucleus, Ituverava, (15) 1, 307-318. http://nucleus.feituverava.com.br/index.php/nucleus/article/view/2878

Bardin, L. (2006). Análise de conteúdo. Lisboa.

Borges, L. F. P. (2017). Educação, escola e humanização em Marx, Engels e Lukács. Revista Educação em Questão. (55) 45, 101-126. https://periodicos.ufrn.br/educacaoemquestao/article/view/12747

Brasil. (2004). Decreto $n^{\circ} 5.154$, de 23 de julho de 2004. Regulamenta o $§ 2^{\text {o }}$ do art. 36 e os arts. 39 a 41 da Lei $n^{\circ} 9.394$, de 20 de dezembro de 1996 , que estabelece as diretrizes e bases da educação nacional, e dá outras providências. http://www.planalto.gov.br/ccivil_03/_ato2004-2006/2004/decreto/d5154.htm 
Brasil. (2018). Lei de diretrizes e bases da educação nacional - LDB. (2). Senado Federal, Coordenação de Edições Técnicas.

Brasil. (2015). Resolução CNE nº 02, de 01 de julho de 2015. Define as Diretrizes Curriculares Nacionais para a formação inicial em nível superior (cursos de licenciatura, cursos de formação pedagógica para graduados e cursos de segunda licenciatura) e para a formação continuada. http://portal.mec.gov.br/index.php?option=com_docman\&view=download\&alias=17719-res-cne-cp-002-03072015\&category_slug=julho-2015-

pdf\&Itemid=30192.

Ciavatta, M. (2014). O ensino integrado, a politecnia e a educação omnilateral. Por que lutamos? Trabalho \& Educação. (23) 1, 187-205. https://periodicos.ufmg.br/index.php/trabedu/article/view/9303.

Frigotto, G. (2012) Educação Omnilateral. In: Caldart, R. S., Pereira, I. B., Alentejano, P. \& Frigotto, G. (Org.). Dicionário da educação do campo. Rio de Janeiro. $267-273$.

Gariglio, J. Â., \& B, S. (2012). Saberes da docência na educação profissional e tecnológica: um estudo sobre o olhar dos professores. Educ. ver. (28) 1, 211236. http://www.scielo.br/scielo.php?script=sci_arttext\&pid=S010246982012000100010\&lng=en\&nrm=iso.

Gasparin, J. L., \& Petenucci, M. C. (2008). Pedagogia histórico-crítica: da teoria à prática no contexto escolar. http://pedagogiaaopedaletra.com/pedagogiahistorico-critica-da-teoria-a-pratica-no-contexto-escolar-de-joao-luiz-gasparin-e-maria-cristina-petenucci/

Gemignani, E. Y. M. Y. (2012). Formação de professores e metodologias ativas de ensino-aprendizagem: ensinar para a compreensão. Fronteiras da Educação. 1 (2). ISSN: 2237-9703. https://www.uniavan.edu.br/uploads/arquivo/K2t3kZ.pdf

Gil, A. C. (2008). Métodos e técnicas de pesquisa social. (6). Atlas.

Godoy, A. S. (1995). Introdução à Pesquisa Qualitativa e suas Possibilidades. Revista de Administração de Empresas. 35 (2), 57-63. http://www.scielo.br/pdf/rae/v35n2/a08v35n2.pdf.

Kuenzer, A. Z. (1997). Ensino Médio e Profissional: as políticas do Estado Neoliberal. Cortez.

Machado, L. R. S. (2015). Diferenciais inovadores na formação de professores para a educação profissional. Revista Brasileira da Educação Profissional e Tecnológica. 1 (1), 8-22. ISSN 2447-1801. http://www2.ifrn.edu.br/ojs/index.php/RBEPT/article/view/2862.

Machado, L. R. S. (2008). Formação de professores para a ept: perspectivas históricas e desafios contemporâneos. In: Brasil. Ministério da Educação. Instituto Nacional de Estudos e Pesquisas Educacionais (inep). Formação de professores para ept: Brasília, 26, 27 e 28 de setembro de $2006.67-82$.

Machado, L. R. S. (2011). O desafio da formação dos professores para a EPT e PROEJA. Educ. Soc. 32 (116), 689-704. http://www.scielo.br/scielo.php?script=sci_arttext\&pid=S010173302011000300005\&lng=en\&nrm=iso.

Moreira, J. R., \& Ribeiro, J. B. P. (2016). Prática pedagógica baseada em metodologia ativa: aprendizagem sob a perspectiva do letramento informacional para o ensino na educação profissional. Outras Palavras, 12, (2), 93-114. http://revista.faculdadeprojecao.edu.br/index.php/Projecao5/article/view/722.

Moura, D. H. (2014). Trabalho e formação docente na educação profissional. Coleção formação pedagógica. (3). IFPR - EAD.

Moura, D. H. (2013). Ensino médio integrado: subsunção aos interesses do capital ou travessia para a formação humana integral? Educ. Pesqui., 39 (3), 705 720. http://www.scielo.br/scielo.php?script=sci_arttext\&pid=S151797022013000300010\&lng=en\&nrm=iso

Ramos, M. N. (2014). História e política da educação profissional. (5). Instituto Federal do Paraná.

Santos, E. H. (2008). Formação de professores para a ept: perspectivas históricas e desafios contemporâneos. In: Brasil. Ministerio da Educação. Instituto Nacional de Estudos e Pesquisas Educacionais (inep). Formação de professores para ept: Brasília, 26, 27 e 28 de setembro de 2006.125 - 140.

Saviani, D. (2011). Pedagogia histórico-crítica: primeiras aproximações. (11). Autores Associados. 